\title{
A CONFIGURAÇÃO PASSIONAL DA CÓLERA NO CONTO "DEPOIS DA AULA", DE LUIZ VILELA
}

\author{
THE PATHEMIC CONFIGURATION OF ANGER IN THE SHORT STORY \\ "DEPOIS DA AULA", BY LUIZ VILELA
}

\author{
Luiz Carlos Migliozzi Ferreira de MELLO ${ }^{1}$ \\ UEL - Universidade Estadual de Londrina
}

\begin{abstract}
RESUMO: O presente trabalho visa a analisar o conto "Depois da aula" de Os melhores contos (1988) de Luiz Vilela. A narrativa conta a história de três alunos que são suspeitos de terem feito um desenho caricato da professora. $\mathrm{O}$ conto mostra as tentativas da professora de obter a delação do responsável pelo desenho. A situação extremamente tensa faz nascer entre os sujeitos, alunos e professora, diferentes estados de alma, tais como desespero, indiferença, medo, cólera, dentre outros. A finalidade deste trabalho é analisar a configuração patêmica da cólera nesse conto. A fundamentação teórica é a Semiótica de linha francesa, mais especificamente a chamada Semiótica das paixões. Não se fará, contudo, uma exposição teórica exaustiva e de forma sistemática de todos os conceitos teóricos utilizados neste artigo. Referir-se-á, no entanto, àqueles conceitos e procedimentos que são considerados chaves à compreensão da cólera. Em outras palavras, a natureza desse trabalho é prática. Quer-se analisar um conto da literatura brasileira, tendo como base a epistemologia passional da cólera apresentada por alguns pesquisadores que tratam do assunto.
\end{abstract}

PALAVRAS-CHAVE: Literatura Brasileira; Conto; Luiz Vilela; Semiótica das Paixões; Cólera.

ABSTRACT: This paper aims to analyze the short story "Depois da Aula" (Apud Os melhores contos. São Paulo: Global, 1988) by Luiz Vilela. The narrative tells the story of three students who are suspected of having drawn a caricature of the teacher. The short story shows the teacher's attempts to obtain the tipoff of the responsible for the drawing. The extremely tense situation bringeth forth between the subjects, students and the teacher, different states of mind, such as despair, indifference, fear, anger, among others. The purpose of this paper is to analyze the pathemic configuration of anger in this short story. The theoretical foundation of this work is the French Semiotics, more specifically the Semiotics of Passion. There shall not be any profound or systematic conceptual explanation of all the theoretical concepts mentioned in this article. Some notes will be made however when they are necessary to the comprehension of anger in this short story. In other words, the nature of the work is practical. The target is to analyze a short story of Brazilian literature, based on the passionate epistemology of anger as presented by some researchers who deal with this subject.

KEYWORDS: Brazilian Literature; Short Story; Luiz Vilela; Semiotics of Passion; Anger.

\footnotetext{
${ }^{1}$ Graduação em Letras. Mestrado e Doutorado em Semiótica e Linguística pela USP-SP. Pós-Doutorado em Sociossemiótica pela PUC-SP. Atua no Programa de Pós-Graduação (mestrado e doutorado) em Letras da UEL no qual orienta pesquisa em Semiótica Literária.
} 


\section{A configuração patêmica da cólera}

O Novo dicionário Aurélio (2004) dá, como definição de cólera, o seguinte: "Impulso violento contra o que nos ofende, fere ou indigna". Essa definição faz entrever a existência de uma ofensa que pode ser de natureza física ou moral. Mostra também a consequência que advém dessa ofensa: agressividade. Essa aproximação lexemática evidencia que a agressividade acontece como um instinto, como algo não refletido, como um impulso.

Em "Depois da Aula", o sujeito ofendido é Dona Berta, e a ofensa é um desenho dela, de natureza caricata, feito por um aluno: "Era uma mulher, uma mulher de pernas compridas, ossuda, a cabeleira imensa e um grande bigode. Como se não bastassem as semelhanças com o original, o autor ainda havia escrito embaixo, com letras grandes: 'Dona Aberta"”. (VILELA, 1988, p. 201).

Acontece que Dona Berta não sabe quem foi o autor da ofensa. Há, contudo, dois suspeitos, Hugo e Ronaldo. Há também uma menina que sabe quem foi o autor do desenho. Tendo sua honra ferida, Dona Berta coloca-se como o sujeito do querer fazer. Ela quer agora punir o culpado e, assim, estabelecer a justiça.

Cumpre apontar para a distinção entre justiça e vingança. A esse respeito, Greimas e Courtés (1976, p. 491) explicam o seguinte:

Como a justiça, a vingança é uma forma de retribuição negativa (ou punição), exercida na dimensão pragmática, por um Destinador dotado de um poder-fazer absoluto: entretanto, elas não se confundem, pelo fato de recorrerem, a primeira a um Destinador social, a segunda a um Destinador individual.

Embora os limites distintivos entre a justiça e a vingança sejam demarcados do ponto de vista epistemológico, como explicam Greimas e Courtés, no conto, a distinção entre essas duas paixões é muito tênue e, com frequência, os dois estados de alma entrecruzam-se. Isso acontece porque ocorre um sincretismo actancial na imagem projetada de Dona Berta. Por meio de suas atitudes, é possível inferir uma professora (destinador social) que fora desacatada em sala de aula e que precisa restabelecer a justiça e restaurar a imagem do destinador social. Por outro lado, abstrai-se também do texto elementos que mostram uma pessoa (destinador individual) que teve sua honra ferida e que quer se vingar.

Com isso, os limites entre justiça e vingança tornam-se, nesse conto, muito vagos, já que a imagem projetada de Dona Berta oscila entre o social e o individual. Dessa maneira, pode-se falar ora em justiça ora em vingança. Como o objetivo deste trabalho não é discutir essa questão em particular, optou-se por usar o termo justiça de maneira abrangente.

Seja buscando a vingança ou a justiça, Dona Berta coloca-se como sujeito julgador. Os alunos suspeitos (Hugo, Ronaldo e mesmo Gema, já que ela estava presente quando o desenho foi feito), de fato, a veem como o sujeito julgador, como aquele que deve e que pode julgar e punir.

Ressalta-se que nesse simulacro que está sendo criado, há uma espécie de deontologia, um código de moral, que regula as atitudes dos alunos e as ações punitivas dos professores. Sendo assim, Dona Berta é o sujeito julgador e deve punir. Contudo, esse sujeito não está atualizado. Dona Berta não sabe quem é o responsável pela ofensa. O não saber implica seu não poder punir e restabelecer a justiça. Essa situação disfórica de impotência (não poder fazer) é destrutiva: ela acaba com a autoridade da professora em sala de aula, o que poderia suscitar novos atos de desrespeito. É preciso, pois, restabelecer a autoridade e o 
poder de Dona Berta em sala de aula. Para tanto, Dona Berta precisa atualizar-se enquanto sujeito julgador que pode punir e, assim fazendo, restabelecer a justiça.

A menina, Gema, é o sujeito modalizador que pode atualizá-la: basta que confesse quem é o autor do desenho. É por isso que há, no conto, tentativas de manipulação, por parte de Dona Berta, para conseguir a confissão/delação da menina: fato que se concretiza ao final do conto. Porém, o objetivo deste trabalho é observar a configuração da cólera nesse conto.

Com o desenho caricato de Dona Berta, aparece o sentimento de descontentamento. Esse descontentamento só acontece em razão de uma frustração. O Novo dicionário Aurélio (2004) define o verbo frustrar como: "Enganar a expectativa de; iludir; defraudar. Não ter o resultado que se esperava; não sair como se pretendia".

A própria definição desse verbo faz entrever a existência e o rompimento de um contrato fiduciário. No conto, os atores desse contrato são, de um lado, Dona Berta e, de outro lado, os alunos.

A ofensa, concretizada pelo desenho caricato mostra as bases desse contrato. O desenho caricato é índice de desrespeito. Pressupõe-se, então, que as bases do contrato fiduciário era o respeito. Além disso, o código de moral (deontologia) da sociedade suscita que o aluno deve respeitar o professor. Nesse sentido, o desenho caricato mostra não só o rompimento do contrato fiduciário, mas também a decepção do sujeito, por ter sua espera frustrada: o aluno não correspondeu às expectativas idealizadas, criadas, imaginadas pelo sujeito da espera, Dona Berta. Eis o que Greimas (1983, p. 230) denominou um "pseudo contrato" ou um "contrato imaginário". Dona Berta cria poder contar com o respeito do aluno e não com sua rebeldia.

Nessa perspectiva, o aluno que fez a caricatura passa a ser não mais o sujeito coadjuvante, mas um antissujeito. Ou seja, aquele que, ao invés de tentar auxiliar o sujeito para conseguir a sua realização, estar em conjunção com o respeito dos alunos, fato que levaria a um estado de satisfação, age no sentido contrário. Assim, ao invés do aparecimento da satisfação, aparece o sentimento da insatisfação, já que o sujeito está em disjunção com seu objeto-valor: respeito dos alunos.

Com a insatisfação, gerada pelo desrespeito do aluno e pela decepção, por não ter sua espera correspondida, surge, no sujeito de estado, Dona Berta, o sentimento de humilhação.

Esse estado disfórico afeta diretamente a honra do sujeito, que foi humilhado. Destaca-se que o efeito passional da humilhação tem caráter social. O que sustenta a relação interpessoal entre os alunos e a professora é a crença dos alunos no fato de que a professora é um sujeito julgador que pode e deve julgar e punir, restabelecendo, assim, a justiça. Se esse sujeito professora foi desrespeitado, isto é, se o contrato fiduciário do respeito foi rompido e esse sujeito humilhado não pune, não consegue restabelecer a justiça, não consegue se manter como sujeito julgador, pode ocorrer uma crise fiduciária coletiva. Em outras palavras, os sujeitos-alunos podem deixar de crer na competência do sujeito julgador, o que seria destituir a figura do professor de sujeito julgador. Portanto, a punição desse aluno, que rompeu com o contrato fiduciário, é vista como uma maneira de conseguir o reequilíbrio passional que levaria a um reequilíbrio de confiança, uma espécie de restauração da competência do sujeito julgador. Assim, como se afirmou anteriormente, essa punição tem um caráter social.

Pode-se afirmar que desse estado disfórico de humilhação surge um sujeito que quer punir, que quer vingar-se, que quer fazer justiça: “- Vocês vão me pagar caro...” (VILELA, 1988, p. 205). Começa, nesse momento, o percurso da instauração do sujeito do fazer.

Todavia, o que existe até esse momento é um sujeito virtual. O sujeito quer e deve punir. No entanto, ele não pode punir, já que desconhece quem o desrespeitou. É nesse momento que o sujeito-professora instaura-se como sujeito manipulador. Sua missão agora é 
convencer Gema a confessar o nome do autor da caricatura. Esse saber é atualizante, já que levaria a um poder ser: saber quem fez a caricatura é a única informação que falta para a instauração do sujeito do fazer.

A professora, sujeito manipulador, inicia o programa narrativo da confissão ou da delação. A estratégia desse sujeito é a manipulação pela sedução. Contudo, Gema não se deixa manipular, pois não acredita nas promessas de não punição da professora. A imagem de pessoa boazinha que Dona Berta passa de si é percebida como falsidade pelos alunos:

Seria muito mais fácil - continuou a professora. - Seria muito melhor para todos. Vocês iriam embora, e pronto, não haveria nada. Não, não haveria não. Era capaz. Acreditava muito nisso. Dona Berta era tão boazinha, né? Ela não faria nada. Era bem capaz mesmo. Como se não a conhecessem. Quem ia ser bobo de acreditar? Claro que ela faria alguma coisa. Só não podiam saber o quê. Mas é claro que ela faria. Todo mundo sabia como ela era. Não deixaria a coisa ficar só por isso. Dona Berta era cruel e vingativa. Ainda mais uma coisa daquelas. (VILELA, 1988, p. 203).

O texto mostra que Gema, por meio de um fluxo de pensamento (discurso indireto livre), tenta justificar, reiterar seu não querer ser, ou seja, seu não querer confessar o autor do desenho, fato que impediria a atualização de Dona Berta como sujeito do fazer. Observe-se:

Pensando bem, ela só podia ser assim: uma mulher que, além de tão feia, ainda era burra. Tinha que ser mesmo cruel e vingativa. E devia ser por isso também que a perseguia - porque ela era bonita e inteligente. Só podia ser, pois era aluna e fazia sempre tudo direitinho. E Dona Berta nunca lhe dava as notas que merecia, eram sempre abaixo das notas de Hugo, que ela vivia protegendo. E por que o protegia? Muito claro: só para provocá-la. Via isso muito bem. Via perfeitamente por que Dona Berta fazia certas coisas. E às vezes ela nem disfarçava. Dona Berta devia ter uma raiva dela - uma raiva imensa. Só porque ela era uma menina linda, de cabelos loiros e olhos verdes, e que todos os meninos viviam paquerando. Podia imaginar como fora Dona Berta em menina: nenhum menino devia se interessar por ela; devia ter sido uma menina comprida, desengonçada, feia, todo mundo fazendo piadas com ela. Dona Berta não se casara. Quem iria se apaixonar por uma mulher como aquela? Não tinha jeito nem de pensar. Se ainda fosse inteligente ou boazinha. Mas nem isso. Era burra e ruim. Desde o começo que a perseguia. (VILELA, 1988, p. 204).

Nesse simulacro criado por Gema, Dona Berta é uma pessoa burra, vingativa, feia e que a perseguia. Esse saber sobremodaliza o não querer ser de Gema. Uma pessoa com tais características não merece ser ajudada por ela. Ao contrário, tal pessoa precisa so frer. A partir dessa reflexão de Gema, ela julga-se prejudicada pelas atitudes de Dona Berta no passado e instaura-se como o sujeito do não querer fazer. Como se apontou anteriormente, é isso que coloca Gema como um antissujeito no percurso narrativo do conto.

Na passagem acima, destaca-se o seguinte trecho: "E Dona Berta nunca lhe dava as notas que merecia, eram sempre abaixo das notas de Hugo, que ela vivia protegendo". Essa passagem suscita outra paixão: a inveja. Gema sente inveja de Hugo, um dos suspeitos de ter feito o desenho. Essa paixão será crucial para compreender o desfecho de conto.

Greimas e Fontanille (1993, p. 14-15) explicam que um "estado de coisas" leva a um "estado de alma". Esse simulacro tensivo que está sendo criado entre Dona Berta e Gema faz 
surgir uma nova paixão: o sadismo. Gema sente prazer em ver Dona Berta sofrer. O simulacro tensivo criado por Dona Berta é recebido e sentido por Gema como um simulacro eufórico. Do sentir ao conhecer: Gema sente o simulacro tensivo de Dona Berta e reconhece que ali estão as condições necessárias para o surgimento da sua vingança. É com esse desejo de vingança que surge o sadismo: "Agora chegara sua vez. Queria ver como Dona Berta faria. Ela já estava até com voz de choro. Pois queria vê-la chorar. Queria vê-la chorando ali, na frente dos três. Queria ver Dona Berta humilhada e vencida, pagando tudo o que fizera de ruim”. (VILELA, 1988, p. 204).

Observem-se agora algumas definições dadas pelo O Novo dicionário Aurélio (2004) que definem o verbo vingar: "Causar a punição de; castigar, punir. Tirar desforço ou desforra de, desafrontar. Promover a reparação de; reparar. Vencer, dominar, subjugar. Lutar por; defender, sustentar. Indenizar, compensar, galardoar; consolar".

Todas essas aproximações lexemáticas apontam para o que Greimas (1983, p. 241) definiu como uma "regulação de paixão". Gema julga que foi prejudicada por Dona Berta, que sua honra foi ferida e tem agora não só a oportunidade, mas também o dever de receber uma "indenização moral" (GREIMAS, 1983, p. 242). É sua chance de restabelecer o "equilíbrio passional" (GREIMAS, 1983, p. 241) que fora perturbado por Dona Berta. E isso se faz não denunciando o autor do desenho. Ressalta-se, mais uma vez, que esse saber é atualizante, isto é, instauraria Dona Berta como o sujeito do poder ser. Não dar o gosto à Dona Berta de punir o responsável pelo desenho e automaticamente deixar uma dúvida sobre a capacidade de liderança, de controle, de Dona Berta sobre os alunos é a vingança de Gema.

Após várias tentativas frustradas por parte da professora de tentar seduzir a aluna a lhe passar esse saber, surge uma nova paixão: o desespero de Dona Berta. Saber da necessidade de ter de se instaurar como o sujeito do fazer (saber dever ser): "Não sabia qual dos três o tinha feito. Mas saberia. Oh, se saberia - nem que tivesse de levar o resto de sua vida para descobrir isso. E fora esse o motivo por que mantivera os três ali na sala depois da aula" (VILELA, 1988, p. 201), somado a outro saber, a consciência de não poder se instaurar como esse sujeito do fazer (saber não poder ser): "não seria mesmo fácil para Dona Berta saber" (VILELA, 1988, p. 203), faz surgir o desespero: "Por quê, Geminha? Por que você não quer dizer?...E a voz da professora tinha agora um tom quase do choro" (VILELA, 1988, p. 203). Em outras palavras, saber dever ser + saber não poder ser $=$ desespero.

Tendo saboreado a vingança por algum tempo, a paixão do sadismo, que dominava Gema, sede espaço a outra paixão: a compaixão. Gema deixa de ter prazer em ver Dona Berta sofrer. A configuração acima que levou ao desespero (saber dever ser + saber não poder ser = desespero) é agora transformada e surge a compaixão. Assim, saber dever ser + saber não poder ser $=$ desespero > compaixão, assim discursivizada: "A menina ergueu os olhos e fitou a professora: e então, por um instante, teve pena dela: pena de sua feiura, de seus olhos inchados e vermelhos, de seu ar de súplica e desamparo" (VILELA, 1988, p. 204).

Essa configuração passional torna bastante clara as observações de Fontanille (1986, p.12), em "Le tumulte modal: de la macro-syntaxe a la micro-syntaxe passionelle" sobre a existência de uma "sintaxe intermodal". Mais do que isso, essa configuração passional, que desembocou na paixão da compaixão, parece confirmar essa hipótese: "J'aventure ici l'hypothèse suivante: les passions ne s'engendrent pas à partir de modalités isolées, ni même de faisceaux de modalités, mais à partir d'une syntaxe inter-modale".

Ressalta-se, no entanto, que Fontanille (1986, p.12) não toma para si a originalidade dessa ideia. Ao contrário, cita outros autores que igualmente a defendem: "Cette idée d'une syntaxe inter-modale n'a en elle-même rien d'original; elle est présente, explicitement ou 
implicitement, chez tous ceux qui ont tant soit peu étudié les passions (FONTANILLE, 1980; GREIMAS, 1981; MARSCIANI, 1984; PARRET, 1986).

Fontanille, porém, aponta para um aspecto diferente dessa sintaxe intermodal. É que para Fontanille (1986, p.12), essa sintaxe intermodal está mesmo no núcleo dos efeitos passionais: "Mais elle [a sintaxe intermodal] n'est exploitée que comme um moment de la description, voire comme une méthode d'approche, et non comme le coeur même de l'effect passionnel".

Essa afirmação de Fontanille parece ficar muito evidente nesse conto, porque, para compreender como se deu o aparecimento da compaixão, é necessário perceber o elo que une a microssintaxe e a macro. Para se compreender como se deu a configuração da compaixão nesse texto, a) é preciso compreender a microssintaxe do sadismo: isto é, como uma posição modal do sujeito (Gema não querer dizer o nome do autor do desenho) gera outra posição modal (Gema querer vingar-se de sua professora). Note-se que essa hierarquização aconteceu no interior da configuração do sadismo. Eis a definição de microssintaxe. Para compreender, ainda, como se deu a configuração da compaixão, b) é preciso compreender também a macrossintaxe: isto é, como o sujeito passou da paixão do sadismo à paixão da compaixão. Note-se que houve passagem de uma paixão à outra. Eis a definição de macrossintaxe.

Como afirmou Fontanille (1986, p.20), não são os arranjos modais que produzem um efeito passional: "Ils [os arranjos modais] ne se convertissent en configurations passionnelles que dans la mesure où une micro-syntaxe peut y être projetée". A configuração passional aparece ora como um elo englobado na macrossintaxe, ora como um sintagma que engloba a microssintaxe.

Mesmo tocada por esse sentimento de compaixão, Gema não revela quem fez o desenho. Há um tom de mistério no texto nesse momento. Há um sentimento que a impede de dizer que foi Ronaldo quem fez o desenho. Há "alguma coisa obscura, mais profunda e mais forte do que a compaixão que sentira" (VILELA, 1988, p. 204) pela professora.

Nesse momento, a professora percebe o gosto da vingança nos olhos de Gema. É o momento em que a manipulação por sedução, usada por Dona Berta até esse momento para convencer Gema a dizer quem havia feito o desenho, revela-se como uma falsidade, e Dona Berta revela sua intenção, que até então era secreta: punir aqueles alunos, sancioná-los negativamente: "A professora notou: viu nos olhos da menina um brilho diferente, uma fixidez mórbida, um começo de sorriso. E então a expressão de súplica e desamparo sumiu - e quando sua voz se ouviu de novo, tinha um tom assustador: - Vocês vão me pagar caro..." (VILELA, 1988, p. 205).

Após a declaração dessa ameaça, os alunos passam a crer que Dona Berta pode punilos. Acreditam que ela tenha se atualizado enquanto sujeito do fazer, e os alunos aguardam a punição. Porém, ao invés da punição, vem o silêncio e a inércia de Dona Berta: "Não esperavam por aquilo; depois daquela ameaça, tinham certeza de que ela faria alguma coisa com eles. Em vez disso, pegava um livro e calmamente começava a ler. Não entenderam. O que ela estava planejando". (VILELA, 1988, p. 205).

Nesse momento, é revelado o sentimento que impedira Gema de contar que foi Ronaldo quem fizera o desenho. É que Gema tem uma admiração e uma paixão (aqui no sentido popular da palavra) secreta por Ronaldo.

A admiração que Gema sente por Ronaldo advém de suas atitudes desleixadas e inesperadas: "Sempre sentira uma confusa admiração por Ronaldo - admiração por seu desleixo, suas respostas inesperadas aos professores, suas artes improvisadas, como aquela: em menos de cinco minutos fizera o desenho". (VILELA, 1988, p. 206). 
A paixão que Gema sente por Ronaldo se dá em razão da ousadia do rapaz: "Muitos viviam olhando para seus seios e suas coxas. Mas Ronaldo fora o único que tivera a coragem de chamá-la até aquele lugar escondido e fazer aquilo" (VILELA, 1988, p. 206).

Ronaldo também tinha esse desejo sexual por Gema: "Percebia que ele vivia doido para fazer de novo. Era só ela topar" (VILELA, 1988, p. 206). Tanto Ronaldo como Gema sentem-se como objetos-valor com os quais queriam entrar em conjunção. Revelar à Dona Berta que foi Ronaldo quem fizera o desenho seria romper com a cumplicidade existente entre os dois. Isso poderia levar Ronaldo a não mais querer entrar em conjunção com o objeto-valor Gema.

A suspensão, mesmo que temporária, da punição de Dona Berta faz surgir entre os alunos outra paixão: o medo: "O progressivo escurecer lá fora, e o impassível silêncio da professora lendo o livro na frente, foram criando entre os meninos um clima de nervosismo e pânico, que finalmente explodiu através de Hugo". (VILELA, 1988, p. 207).

Com o medo, aparecem as trocas e acusações entre os alunos: uma forma de evitar a punição:

Ele [Hugo] se levantou e gritava para a menina:

- Você viu, Gema! Por que você não fala? Você viu que foi Ronaldo! Você sabe que foi ele!

- Então fala, Gema, então fala que foi eu. Você viu, então fala.

- Sem-vergonha! - gritou Hugo para Ronaldo. - Covarde! Por que você não fala?

- A Gema vai falar. Ela viu. Fala, Gema.

- Você também é uma covarde! - gritou Hugo para ela.

- Só porque eu tiro notas melhores que você, é por isso que você não quer contar, covarde!

- Conta, Gema.

- Vocês todos são covardes! Cachorrada! (VILELA, 1988, p. 207).

É só nesse momento que a presença de Dona Berta na sala passa a ser novamente notada: "Fora um grito tão agudo que parecia vibrar ainda agora no silêncio da sala" (VILELA, 1988, p. 207). É nesse momento também que se manifesta o "impulso violento" da cólera, como previsto pelas aproximações lexemáticas a partir das definições do dicionário. A agressividade de Dona Berta se faz notar:

Dona Berta então se levantou e veio andando na direção da menina, os outros dois olhando assustados. Parou em frente à carteira:

-Agora você vai dizer - falou para a menina. - Juro que você vai dizer. Se não disser, eu lhe meto a mão na cara! - a voz subira de repente, fazendo estremecer a sala. (VILELA, 1988, p. 208).

A ameaça da agressividade torna-se tão evidente que o medo toma conta dos alunos. Gema é obrigada agora a dar um nome. A promessa da agressão faz a menina redefinir seu não querer contar quem é o autor do desenho: “- Então, - a professora falou, e sua voz era de gelar: - quem fez o desenho? Foi Hugo ou foi Ronaldo?/Dessa vez, mas sem se mover, sem erguer os olhos, a menina respondeu: - Foi Hugo. (VILELA, 1988, p. 208).

Nesse momento, Dona Berta recebe o saber atualizante e se instaura como sujeito do fazer e passa a poder punir e, assim fazendo, passa a poder fazer justiça. Ressalta-se, no entanto, que a agressão física efetivamente não foi posta em discurso nesse conto. De qualquer maneira, a sintaxe da cólera fica evidenciada. 


\section{Considerações finais}

Ao mentir sobre o nome do autor do desenho, Gema livra-se da agressão de Dona Berta. Contudo, não desestabiliza o contrato fiduciário que tem com Ronaldo, já que a cumplicidade que existe entre eles está preservada. A crença na esperança de que Ronaldo ainda a veja como objeto-valor está inalterada, se não fortalecida com a mentira de Gema: uma clara intenção de poupar o sofrimento de Ronaldo. Além disso, a mentira serve como um expediente de regulação da paixão. Não se pode esquecer de que Hugo ofendeu a honra de Gema e de Ronaldo, chamando-os de covardes, xingou a ambos e disse que Gema o invejava porque ele tirava notas melhores do que as notas dela. Diante dessa situação, surge o efeito de humilhação. Por isso, a delação de Hugo, e não de Ronaldo, irrompe como elemento da restauração da honra, como uma forma de reequilíbrio passional.

\section{REFERÊNCIAS}

Novo dicionário Aurélio. Versão 5.0 Eletrônica - Edição Revista e Atualizada. São Paulo: Positivo Informática, 2004.

GREIMAS, A. J. \& COURTÉS, J. Dicionário de semiótica. São Paulo: Cultrix, 1976.

GREIMAS, A. J. \& FONTANILLE, J. Semiótica das paixões. São Paulo: Ática, 1993.

GREIMAS, A. J. De la colère: étude de sémantique lexicale. In: GREIMAS, A. J. Du sens II. Paris: Seuil, 1983, p. 225-239.

FONTANILLE, J. Le tumulte modal: de la macro-syntaxe la micro-syntaxe passionelle. Actes Sémiotiques: Bulletin, Paris, v. 11, n. 39, p. 12-31, 1986.

VILELA, L. Depois da Aula. In: VILELA, L. Os melhores contos. São Paulo: Global, 1988. 